(2) Open Access Full Text Article

\title{
Albumin concentrations plus neutrophil lymphocyte ratios for predicting overall survival after curative resection for gastric cancer
}

This article was published in the following Dove Press journal:

OncoTargets and Therapy

27 July 2016

Number of times this article has been viewed

\author{
Xiaowei Sun ${ }^{1,2, *}$ \\ Juncheng Wang ${ }^{1,3, *}$ \\ Jianjun Liu' ${ }^{1,2}$ \\ Shangxiang Chen ${ }^{1,2}$ \\ Xuechao Liu',2
}

'State Key Laboratory of Oncology in South China, Sun Yat-sen University

Cancer Center, Collaborative

Innovation Center for Cancer

Medicine, ${ }^{2}$ Department of Gastric and

Pancreatic Surgery, ${ }^{3}$ Department of

Hepatobiliary Oncology, Sun Yat-Sen

University Cancer Center, Guangzhou,

People's Republic of China

*These authors contributed equally to this work
Correspondence: Xiaowei Sun Department of Gastric and Pancreatic Surgery, Sun Yat-Sen University Cancer Center, 65I\# East Dongfeng Road, Guangzhou 510060, Guangdong, People's Republic of China

Fax +862087343123

Email sunxw@sysucc.org.cn
Background: In patients with gastric cancer (GC), survival is poor, given the late diagnosis. Risk-stratifying these patients earlier could help improve care. We determined whether combining preoperative albumin concentration and the neutrophil lymphocyte ratio (COA-NLR) could predict overall survival (OS) better than other prognostic indexes.

Methods: We calculated the COA-NLR and other prognostic indexes with data obtained within 1 week before surgery in a retrospective analysis of patients with GC undergoing curative resection between September 2000 and November 2012. Patients with concentrations of hypoalbuminemia above $35 \mathrm{~g} / \mathrm{L}$ and an NLR value of 2.3 or higher were given a score of 2 . Patients with one of these conditions or neither were allocated scores of 1 or 0 , respectively. Patients were monitored until July 2014.

Results: OS in the 873 eligible patients was $44.9 \%$ in patients with a COA-NLR score of 0 , $29.8 \%$ in patients with a score of 1 , and $20.3 \%$ in patients with a score of $2(P<0.001)$. The COA-NLR score was independently associated with OS (hazard ratio, 1.35; 95\% confidence interval, 1.12 to $1.63 ; P=0.002)$. Moreover, the area under the receiver operating characteristics curve was 0.62 for the COA-NLR, which was significantly higher $(<0.001)$ than that of the NLR ratio $(0.60)$, the Glasgow prognostic score $(0.58)$, and the platelet lymphocyte ratio $(0.54)$. The COA-NLR was especially accurate for patients with stage I-II GC and the three values $(0,1$, and 2) divided patients into subgroups more accurately than did the other indexes (area under the curve value: $0.66, P<0.001)$.

Conclusion: The preoperative COA-NLR index is useful for predicting postoperative OS in patients with GC and can be used to guide targeted therapy.

Keywords: albumin concentration, neutrophil-to-lymphocyte ratio, gastric cancer, prognosis, adjuvant chemotherapy

\section{Introduction}

Gastric cancer (GC) is one of the most common and deadly malignancies worldwide, with an annual incidence of about 1 million cases. ${ }^{1}$ Although multidisciplinary treatment, including adjuvant chemotherapy and radiotherapy, has advanced, surgical resection remains the main treatment choice. However, overall postoperative survival is still poor, given the relatively late stage at which the diagnosis is usually made.,3 Hence, interest is increasing in identifying high-risk patients as soon as possible to improve clinical decision making and contribute to a more rational targeted therapy.

The American Joint Committee on Cancer tumor-node-metastasis (TNM) system, the reference standard for predicting $\mathrm{GC}$ prognosis, depends on postoperative 
histologic findings. Identifying preoperative indicators of postoperative survival in these patients would thus be valuable.

The host's systemic inflammatory response (SIR) is a critical component of tumor progression. ${ }^{4}$ As a state of chronic inflammation, SIR is an essential component in carcinogenesis, promoting both proliferation and migration. ${ }^{5-7}$ Recent studies have shown that SIR is associated with poor outcomes in various types of cancer..$^{8-10}$

Several SIR-based prognostic indexes have been explored for GC, including the Glasgow prognostic score (GPS), the neutrophil lymphocyte ratio (NLR), and the platelet lymphocyte ratio (PLR). ${ }^{11-13}$ Of these, the GPS is regarded as the most promising predictor of postoperative survival. More than 70 studies worldwide have investigated the relationship between the GPS and postoperative survival in several types of cancer. ${ }^{14}$ Based on elevated serum concentrations of both C-reactive protein (CRP) and hypoalbuminemia, the GPS reflects both systemic inflammation and malnutrition. ${ }^{15}$ Low albumin concentrations are associated with poor survival in GC, and the strength of this association depends on the presence of SIR. ${ }^{16}$ Lien et al also concluded that preoperative serum albumin concentration, in conjunction with TNM stage, accurately predicted long-term outcomes in GC. ${ }^{17}$ In addition, a recent meta-analysis of nine studies concluded that an elevated NLR was associated with poorer rates of survival in GC patients. $^{18}$

Therefore, we hypothesized that an index based on preoperative serum albumin concentration and NLR would predict postoperative survival better than other prognostic scores. The results of our retrospective analysis indicate that the COA-NLR does predict the overall survival (OS) better than other prognostic scores.

\section{Methods}

This study complied with the standards of the Declaration of Helsinki and was approved by the Ethical Committee of Sun Yat-Sen University Cancer Center. Every patient provided written informed consent before being included in this study.

\section{Patient selection}

We retrospectively analyzed data from all patients with GC who underwent curative resection (D2 lymphadenectomy) at the Cancer Center of Sun Yat-Sen University between September 2000 and November 2012. All patients had stage I to III adenocarcinoma of the stomach, confirmed by pathologic analyses of postoperative histological specimens. Cancers were staged according to the seventh edition of the American Joint Committee on Cancer TNM staging system. ${ }^{19}$
After surgery, the patient's case was discussed at a multidisciplinary meeting involving surgeons, oncologists, pathologists, and radiologists. Using current guidelines, patients with high-risk stage II or III GC and no marked comorbidities precluding chemotherapy were offered primarily 5-fluorouracil-based adjuvant chemotherapy. ${ }^{20}$

Patients were excluded if laboratory data were incomplete, if there were clinical evidence of infection or inflammatory conditions, if they had undergone neoadjuvant chemotherapy or radiotherapy, or if they had received preoperative intravenous nutrition or anti-inflammatory therapy.

\section{Data collection}

Within 1 week before surgery, routine laboratory measurements, including serum concentrations of CRP and albumin; and lymphocyte, neutrophil, and platelet counts, were obtained from all patients and logged in the medical record. Performance status (Eastern Cooperative Oncology Group) was recorded at the time of diagnosis. In addition, preoperative body weight loss was recorded, defined as "none", "limited" ( $\leq 10 \%)$, or "severe" $(>10 \%) .{ }^{21}$ Papillary and moderately differentiated histological grades were categorized as well-differentiated cancers, and signet ring cell, mucinous types, and undifferentiated grades were categorized as poorly differentiated cancers. ${ }^{22}$

Patients were followed regularly at 6- to 12-month intervals with laboratory tests, dynamic computed tomography scans, and gastroscopic examinations. The last follow-up date was July 8,2014 . OS was measured from the date of surgery to the date of death or to the last follow-up visit. Thus, data were censored as of July 8, 2014.

The NLR and PLR were defined as the absolute neutrophil count and platelet count, respectively, divided by the absolute lymphocyte count. The GPS was calculated from serum CRP and albumin concentrations. As reported previously, ${ }^{23}$ standard clinical thresholds were used for some common variables, including CRP and albumin concentrations; and lymphocyte, neutrophil, and platelet counts (Table 1).

Patients who had a CRP concentration $>10 \mathrm{mg} / \mathrm{L}$ and an albumin concentration $<35 \mathrm{~g} / \mathrm{L}$ were assigned a score of 2 . Patients with only one or neither of these concentrations were assigned a score of 1 or 0 , respectively. ${ }^{15}$ The COA-NLR was calculated as follows: patients with both hypoalbuminemia $(<35 \mathrm{~g} / \mathrm{L})$ and an elevated NLR $(\geq 2.3)$ were allocated a score of 2 , and patients with one or neither were allocated a score of 1 or 0 , respectively. The optimal thresholds for other variables were defined using the Youden index and receiver operating characteristic (ROC) curve analyses. 
Table I Inflammation-based scoring indexes for predicting postoperative survival in patients with gastric cancer

Scoring system

Score

Neutrophil lymphocyte ratio

Neutrophil count:lymphocyte count $<2.3$

Neutrophil count:lymphocyte count $\geq 2.3$

0

Platelet lymphocyte ratio

Platelet count:lymphocyte count $<117$

Platelet count:lymphocyte count $\geq 117$

Glasgow prognostic score

CRP $(\leq 10 \mathrm{mg} / \mathrm{L})$ and albumin $(\geq 35 \mathrm{~g} / \mathrm{L})$

CRP $(\leq 10 \mathrm{mg} / \mathrm{L})$ and albumin $(<35 \mathrm{~g} / \mathrm{L})$

CRP $(>10 \mathrm{mg} / \mathrm{L})$ and albumin $(\geq 35 \mathrm{~g} / \mathrm{L})$

CRP $(>10 \mathrm{mg} / \mathrm{L})$ and albumin $(<35 \mathrm{~g} / \mathrm{L})$

Combination of albumin concentration + neutrophil: lymphocyte ratio

Albumin ( $\geq 35 \mathrm{~g} / \mathrm{L})$ and neutrophil count:lymphocyte count $<2.30$

Albumin ( $\geq 35 \mathrm{~g} / \mathrm{L})$ and neutrophil count:lymphocyte count $\geq 2.3 \quad$ ।

Albumin $(<35 \mathrm{~g} / \mathrm{L})$ and neutrophil count:lymphocyte count $<2.3 \quad$ ।

Albumin ( $<35 \mathrm{~g} / \mathrm{L})$ and neutrophil count:lymphocyte count $\geq 2.32$

Abbreviation: CRP, C-reactive protein.

\section{Statistical methods}

Patient characteristics are summarized as mean and 95\% confidence interval (CI). Differences among the three groups (ie, patients with prognostic scores of 0,1 , or 2 ) were analyzed with Pearson's chi-squared test. OS was calculated with the Kaplan-Meier method, and differences were assessed by log-rank tests. The Shapiro-Wilk test was used to assess the normality of distribution. If a continuous variable was proven for the assumption of linearity in the logit, it was categorized by the optimal cutoff value. ROC curves were plotted, and the optimum cutoff value for predicting OS was determined with Youden index (maximum [sensitivity + specificity] minus 1). Unadjusted and multivariate analyses were performed to identify potential prognostic factors. Variables significantly associated with OS at the 0.05 level in the unadjusted analysis were considered for inclusion in a multivariate Cox proportional hazards model., ${ }^{9,24,25}$ The discriminatory ability of each prognostic score was expressed as the area under the curve (AUC). All data were analyzed with the SPSS statistical software package, version 19.0 (IBM Corporation, Armonk, NY, USA). Alpha was set at 0.05 , and all tests were two-tailed.

\section{Results}

Of the 1,017 patients evaluated, 96 had incomplete laboratory data, 24 had clinical evidence of infection or inflammatory conditions, 13 had undergone neoadjuvant chemotherapy or radiotherapy, and eleven had received preoperative intravenous nutrition or anti-inflammatory therapy. In the 873 eligible patients (594 males and 279 females), the median (range) age was 59 (19-89) years. Median (range) follow-up period was $36(1-165)$ months. The 471 patients who died before July 8, 2014 (54.0\%) were included in the analysis; $402(46.0 \%)$ patients were alive at the last follow-up. Of the 873 patients, only six patients died of other diseases or reasons and most of the patients died of tumor recurrence and metastasis. During the observation period, 13 of 108 stage I patients died and ten $(9 \%)$ patients died of recurrence of cancer at last follow-up.

The COA-NLR score was 0 for 488 patients, 1 for 328 patients, and 2 for 57 patients. Albumin concentrations and the NLR were inversely correlated $(r=-0.14 ; P<0.001)$. Groups with the three scores differed significantly according to mean age, tumor size, tumor location, performance status, preoperative body weight loss, metastatic lymph node ratio, histological grade, and TNM stage (Table 2) and by OS. OS was $44.9 \%$ in patients with a COA-NLR score of $0,29.8 \%$ in patients with a score of 1 , and $20.3 \%$ in patients with a score of $2(P<0.001)$. Mean survival was also significantly longer in patients with a COA-NLR of 0 ( 87.7 months) than in those with a score of 1 (65.3 months) or 2 (51.8 months; Table 3; Figure 1).

Unadjusted analysis indicated that age, tumor size, tumor location, preoperative body weight loss, histological grade, metastatic lymph node ratio, TNM stage, neutrophils, CRP, albumin, NLR, PLR, GPS, and COA-NLR score were associated with OS. Multivariate analysis indicated that COA-NLR score was independently associated with OS (hazard ratio [HR], $1.35 ; 95 \% \mathrm{CI}, 1.12$ to $1.63 ; P=0.002$ ), as were TNM stage, metastatic lymph node ratio, preoperative body weight loss, histological grade, tumor location, and age (Table 4).

Because the COA-NLR was closely associated with the above variables, its prognostic value was further investigated with subgroup analysis. Prognostic significance was still maintained when patients were stratified by age ( $<60$ years, $P=0.002$; $\geq 60$ years, $P<0.001$ ), tumor location (upper stomach, $P=0.009$; middle stomach, $P=0.30$, lower stomach, $P<0.001$ ), preoperative body weight loss (none, $P<0.001$; limited, $P=0.090$; severe, $P=0.002$ ), histological grade (well differentiated, $P<0.001$; poorly differentiated, $P<0.001)$, metastatic lymph node ratio $(<0.1$, $P<0.001 ; \geq 0.1, P=0.02$ ), and TNM stage (stage I, $P=0.001$; stage II, $P=0.006$; stage III, $P=0.02$ ).

To further assess the discriminatory ability of the indexes, we compared the areas under the ROC curve. The COA-NLR index had a significantly higher AUC value than the others, 
Table 2 Relationships between COA-NLR score and clinicopathologic characteristics of 873 patients undergoing curative resection without neoadjuvant treatment for gastric cancer

\begin{tabular}{|c|c|c|c|c|}
\hline \multirow[t]{2}{*}{ Characteristic } & \multicolumn{3}{|c|}{ COA-NLR score } & \multirow[t]{2}{*}{$P$-value } \\
\hline & $\begin{array}{l}\text { Zero } \\
(n=488)\end{array}$ & $\begin{array}{l}I \\
(n=328)\end{array}$ & $\begin{array}{l}2 \\
(n=57)\end{array}$ & \\
\hline Sex & & & & 0.06 \\
\hline Male & 317 & 239 & 38 & \\
\hline Female & $17 \mid$ & 89 & 19 & \\
\hline Age (years) & & & & 0.001 \\
\hline$<60$ & 291 & 156 & 25 & \\
\hline$\geq 60$ & 197 & 172 & 32 & \\
\hline Tumor size $(\mathrm{cm})$ & & & & $<0.001$ \\
\hline$\leq 3$ & 182 & 73 & 10 & \\
\hline$>3$ & 306 & 255 & 47 & \\
\hline Tumor location & & & & 0.02 \\
\hline Upper & 182 & 159 & 29 & \\
\hline Middle & 100 & 54 & 8 & \\
\hline Lower & 206 & 115 & 20 & \\
\hline Performance status & & & & 0.04 \\
\hline 0 & 152 & 92 & 12 & \\
\hline 1 & 324 & 232 & $4 I$ & \\
\hline 2 & 12 & 4 & 4 & \\
\hline Preoperative weight loss & & & & 0.02 \\
\hline None & 250 & 157 & 26 & \\
\hline Limited & 195 & 136 & 18 & \\
\hline Severe & 43 & 35 & 13 & \\
\hline Adjuvant chemotherapy & & & & 0.08 \\
\hline No & 178 & 98 & 15 & \\
\hline Yes & 310 & 230 & 42 & \\
\hline Histological grade & & & & 0.004 \\
\hline Well differentiated & 91 & 87 & 19 & \\
\hline Poorly differentiated & 397 & 241 & 38 & \\
\hline Metastatic lymph node ratio & & & & $<0.001$ \\
\hline$<0.1$ & 222 & 99 & 20 & \\
\hline$\geq 0.1$ & 266 & 229 & 37 & \\
\hline TNM stage (I/II/III) & & & & $<0.001$ \\
\hline I & 82 & 23 & 3 & \\
\hline II & 114 & 59 & 12 & \\
\hline III & 292 & 246 & 42 & \\
\hline
\end{tabular}

Abbreviations: COA-NLR, the combination of albumin level and neutrophil lymphocyte ratio; TNM, tumor-node-metastasis staging.

including the GPS, which has been regarded as a prognostic milestone (Table 5; Figure 2). Of note, in stage I-II GC, the COA-NLR was superior to other established inflammationbased prognostic indexes in terms of its prognostic ability, with a higher AUC value $(0.66 ; P<0.001)$, and it divided patients into subgroups more accurately (all $P$-values for association with OS were $<0.05$; Figure 3 ). In addition, the AUC value of the COA-NLR was the highest for patients with stage I GC (AUC value: 0.72; $P=0.009$ ).

\section{Discussion}

We determined the prognostic value of the COA-NLR for patients with GC. The COA-NLR score had a greater AUC
Table 3 Factors affecting overall survival among 873 patients undergoing curative resection without neoadjuvant treatment for gastric cancer

\begin{tabular}{|c|c|c|c|}
\hline Characteristic & $\begin{array}{l}\text { Patients, } \\
\text { n (\%) }\end{array}$ & $\begin{array}{l}\text { Overall survival, } \\
\text { months }(95 \% \mathrm{Cl})\end{array}$ & $P$-value ${ }^{a}$ \\
\hline Sex & & & 0.46 \\
\hline Male & $594(68.0)$ & 79.7 (73.3 to 86.0) & \\
\hline Female & $279(32.0)$ & 83.3 (74.5 to 92.1$)$ & \\
\hline Age (years) & & & $<0.001$ \\
\hline$<60$ & $472(54.1)$ & $87.9(81.1$ to 94.8$)$ & \\
\hline$\geq 60$ & $40 I(45.9)$ & $67.8(60.5$ to 75.1$)$ & \\
\hline Tumor size $(\mathrm{cm})$ & & & $<0.001$ \\
\hline$\leq 3$ & $265(30.4)$ & 94.5 (85.6 to 103.4) & \\
\hline$>3$ & $608(69.6)$ & 71.1 (65.I to 77.I) & \\
\hline Tumor location & & & $<0.001$ \\
\hline Upper & $370(42.4)$ & $54.3(48.0$ to 60.6$)$ & \\
\hline Middle & $162(18.6)$ & 81.9 (70.0 to 93.9$)$ & \\
\hline Lower & $341(39.1)$ & $97.5(89.5$ to 105.5$)$ & \\
\hline $\begin{array}{l}\text { Performance } \\
\text { status }^{\mathrm{b}}\end{array}$ & & & 0.98 \\
\hline 0 & $256(29.3)$ & 74.7 (64.9 to 84.4$)$ & \\
\hline 1 & $597(68.4)$ & 79.5 (73.3 to 85.6) & \\
\hline 2 & $20(2.3)$ & $71.3(42.3$ to 100.3$)$ & \\
\hline $\begin{array}{l}\text { Preoperative } \\
\text { weight loss }\end{array}$ & & & 0.001 \\
\hline None & $433(49.6)$ & $87.9(80.4$ to 95.3$)$ & \\
\hline Limited ( $\leq 10 \%)$ & $349(40.0)$ & 71.0 (53.5 to 78.4$)$ & \\
\hline Severe $(>10 \%)$ & $91(10.4)$ & $60.0(45.2$ to 74.7$)$ & \\
\hline $\begin{array}{l}\text { Adjuvant } \\
\text { chemotherapy }\end{array}$ & & & 0.11 \\
\hline No & $291(33.3)$ & 74.5 (65.3 to 83.7$)$ & \\
\hline Yes & $582(66.7)$ & 80.2 (74.2 to 86.2$)$ & \\
\hline $\begin{array}{l}\text { Histological } \\
\text { grade }^{c}\end{array}$ & & & 0.03 \\
\hline Well differentiated & $197(22.6)$ & 82.4 (72.9 to 92.0$)$ & \\
\hline Poorly differentiated & $676(77.4)$ & 76.9 (71.0 to 82.8$)$ & \\
\hline Metastatic lymph & & & $<0.001$ \\
\hline
\end{tabular}

node ratio

$<0.1$

$\geq 0.1$

TNM stage (I/II/III)

34 I (39.I) II $\quad$ I6.2 (I09.0 to I23.5)

532 (60.9) 52.4 (46.8 to 58.1$)$

I

II

III

Neutrophil

count, $10^{9} / \mathrm{L}$

$<7.5$

$\geq 7.5$

Lymphocyte

count, $10^{9} / \mathrm{L}$

$<3$

$\geq 3$

Platelet

count, $10^{\circ} / \mathrm{L}$

$<400$

$\geq 400$

C-reactive

protein, $\mathrm{mg} / \mathrm{L}$

$\leq 10 \quad 494(56.6) \quad 47.6(44.5$ to 50.7$)$

$>10 \quad 107(12.3) \quad 28.7(24.1$ to 33.4$)$
0.72

$108(12.4) \quad 122.7$ (II5.2 to I30.I)

185 (2I.2) III.0 (100.5 to I2I.6)

$580(66.4) \quad 55.8$ (50.2 to 61.4$)$

$812(93.0) \quad 82.2$ (76.8 to 87.6$)$

$6 I$ (7.0) $\quad 37.1$ (26.I to 48.1$)$

0.70

$812(93.0) \quad 79.5$ (74.I to 84.8$)$

61 (7.0) $\quad 70.8$ (54.7 to 86.9$)$

803 (92.0) 79.5 (74.I to 84.9)

$70(8.0) \quad 73.4(57.7$ to 89.0$)$

(Continued) 
Table 3 (Continued)

\begin{tabular}{|c|c|c|c|}
\hline Characteristic & $\begin{array}{l}\text { Patients, } \\
\text { n (\%) }\end{array}$ & $\begin{array}{l}\text { Overall survival, } \\
\text { months }(95 \% \mathrm{Cl})\end{array}$ & $P$-value ${ }^{a}$ \\
\hline Albumin, g/L & & & $<0.001$ \\
\hline$<35$ & $98(I I .2)$ & $58.5(44.5$ to 72.4$)$ & \\
\hline$\geq 35$ & $775(88.8)$ & $80.4(75.1$ to 85.7$)$ & \\
\hline Neutrophil & & & $<0.001$ \\
\hline \multicolumn{4}{|c|}{ lymphocyte ratio } \\
\hline$<2.3$ & $529(60.6)$ & 86.1 (79.8 to 92.4$)$ & \\
\hline$\geq 2.3$ & $344(39.4)$ & 64.0 (56.3 to 71.7$)$ & \\
\hline Platelet & & & 0.009 \\
\hline \multicolumn{4}{|c|}{ lymphocyte ratio } \\
\hline$<117$ & $365(4 I .8)$ & 84.9 (77.2 to 92.7$)$ & \\
\hline$\geq 117$ & $508(58.2)$ & $74.4(67.7$ to 81.2$)$ & \\
\hline Glasgow & & & $<0.001$ \\
\hline \multicolumn{4}{|c|}{ prognostic score } \\
\hline 0 & $464(53.2)$ & $48.3(45.1$ to 51.5$)$ & \\
\hline I & $98(11.2)$ & 33.2 (27.6 to 38.8 ) & \\
\hline 2 & $39(4.5)$ & 23.8 (16.8 to 30.8$)$ & \\
\hline COA-NLR & & & $<0.001$ \\
\hline 0 & 488 (55.9) & $87.7(8 I . I$ to 94.2$)$ & \\
\hline I & $328(37.6)$ & 65.3 (57.6 to 73.1$)$ & \\
\hline 2 & $57(6.5)$ & 51.8 (34.9 to 68.7$)$ & \\
\hline
\end{tabular}

Notes: ${ }^{a}$ Kaplan-Meier survival analysis. ${ }^{b}$ Eastern Cooperative Oncology Group. cPapillary and moderately differentiated histological grades were categorized as well-differentiated cancers, and signet ring cell, mucinous types, and undifferentiated grades were categorized as poorly differentiated cancers.

Abbreviations: $\mathrm{Cl}$, confidence interval; COA-NLR, the combination of albumin level and neutrophil lymphocyte ratio; TNM, tumor-node-metastasis staging.

than the other indexes studied and it was associated with more aggressive tumor features. We believe it can be used as an independent marker of poor prognosis in patients undergoing curative resection for GC without neoadjuvant treatment.

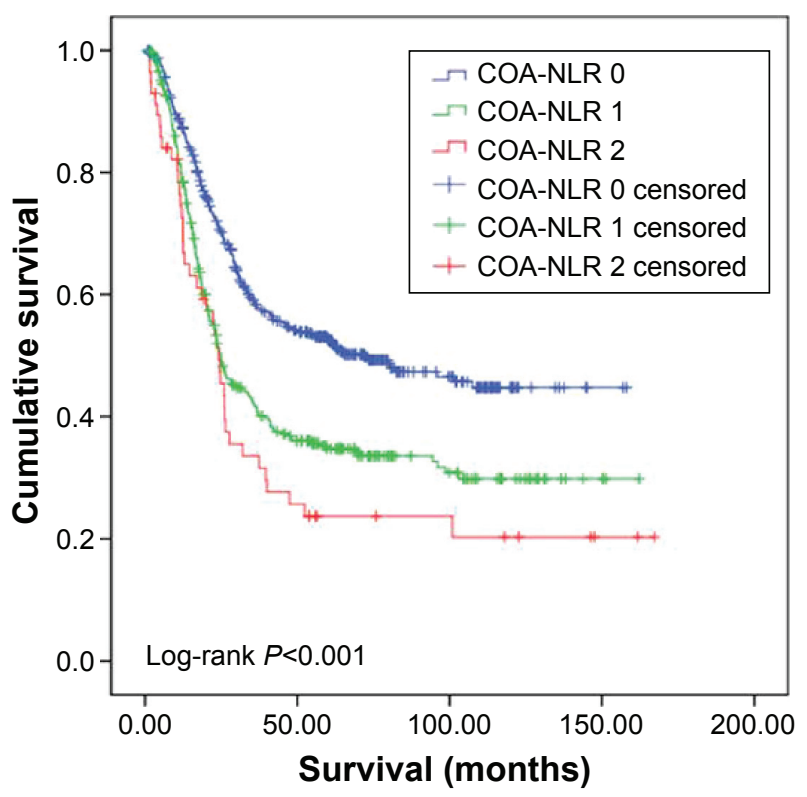

Figure I Cumulative survival of 873 patients undergoing curative resection without neoadjuvant treatment for gastric cancer stratified by the preoperative combination of albumin concentration and the neutrophil lymphocyte ratio (COA-NLR; $P<0.00$ I). Abbreviation: COA-NLR, the combination of albumin level and neutrophil lymphocyte ratio.
The link between inflammation and cancer is well established, although the underlying mechanism is not completely understood. Inflammatory responses can induce chronic oxidative stress and produce oxygen-free radicals, which can stimulate carcinogenesis, proliferation, and progression. ${ }^{26}$ Furthermore, proinflammatory cytokines release tumorassociated leukocytes that can generate various inflammatory cytokines, including tumor necrosis factor-alpha, interleukin, and vascular endothelial growth factor, which facilitate cancer growth, invasion, and metastasis $\mathrm{s}^{7,27,28}$ and suppress antitumor immunity, which further promotes proliferation and progression. ${ }^{29}$

Inflammation-based prognostic indexes, such as the NLR, PLR, and GPS, have been reported to have value in patients with various types of cancer, including GC..$^{30-32}$ In the metaanalysis described earlier of ten studies with a pooled sample size of 2,952 patients, OS was significantly better in patients with low NLR values, and the pooled HR was significant (HR, 1.83; 95\% CI, 1.62 to 2.07 ). ${ }^{33}$

Hypoalbuminemia, as a state of malnutrition, also independently predicts survival in patients with GC..$^{16}$ Albumin, which preferentially accumulates in tumor tissue, is a major energy and nutrition source for tumor growth. Additionally, hypoalbuminemia can impair cellular immunity, which eventually results in a poor prognosis. Al-Shaiba et al confirmed an association between hypoalbuminemia, inflammation, and poor outcome in patients with colorectal liver metastases. ${ }^{34}$ Thus, albumin concentration is not only a nutritional marker, it is also an inflammatory response marker. Accumulating evidence indicates that hypoalbuminemia is associated with poor survival in several primary malignancies, including GC. ${ }^{35-37}$

Therefore, we speculated that an index based on preoperative serum albumin concentration and the NLR might be a promising tool in predicting outcomes in GC. In the current study, we found that the COA-NLR was a valuable predictor of OS independent of TNM stage. Furthermore, it was significantly associated with some variables indicating poor prognosis, including higher TNM stage, more metastatic lymph nodes, and larger tumor size. Obviously, an elevated COA-NLR score was associated with more aggressive tumor features. In subgroup analyses, the prognostic accuracy of the COA-NLR was still substantial, although it was not significant in patients with tumors located in the middle stomach and limited preoperative body weight loss. However, only eight patients with tumors located in the middle stomach and only 18 with preoperative weight loss had a COA-NLR score of 2, so these results should be viewed with caution.

The PLR did not independently predict OS in the multivariate model that included the COA-NLR. Therefore, these 
Table 4 Univariate and multivariate analyses of risk factors for overall survival in 873 patients undergoing curative resection without neoadjuvant treatment for gastric cancer

\begin{tabular}{|c|c|c|c|c|}
\hline \multirow[t]{2}{*}{ Characteristic } & \multicolumn{2}{|l|}{ Unadjusted analysis } & \multicolumn{2}{|c|}{ Multivariate analysis } \\
\hline & HR $(95 \% \mathrm{Cl})$ & $P$-value & HR $(95 \% \mathrm{Cl})$ & $P$-value \\
\hline Sex (male/female) & $0.93(0.764$ to 1.13$)$ & 0.46 & - & \\
\hline Age $(<60 / \geq 60$ years $)$ & $\mathrm{I} .54(\mathrm{I} .28 \mathrm{I}$ to $\mathrm{I} .84)$ & $<0.001$ & $1.60(1.28$ to 1.98$)$ & $<0.001$ \\
\hline Tumor size $(\leq 3 />3 \mathrm{~cm})$ & $1.75(1.41$ to 2.17$)$ & $<0.001$ & $0.92(0.7 \mid$ to I.2I) & 0.56 \\
\hline Tumor location (upper/middle/lower) & $0.67(0.61$ to 0.75$)$ & $<0.001$ & 0.79 (0.69 to 0.89$)$ & $<0.001$ \\
\hline Performance status $(0 / 1 / 2)$ & $1.02(0.85$ to 1.23$)$ & 0.84 & - & \\
\hline Preoperative body weight loss (no/limited/severe) & $1.29(1.13$ to 1.47$)$ & $<0.001$ & $1.20(\mathrm{I} .03$ to $\mathrm{I} .4 \mathrm{I})$ & 0.02 \\
\hline Adjuvant chemotherapy (no/yes) & $0.86(0.7 \mathrm{I}$ to I.04) & 0.11 & - & \\
\hline Histological grade (well/poorly differentiated) & $1.28(1.03$ to 1.61$)$ & 0.03 & 1.49 ( 1.10 to 2.02$)$ & 0.009 \\
\hline Metastatic lymph node ratio $(<0.1 / \geq 0.1)$ & 4.26 (3.38 to 5.36$)$ & $<0.001$ & 2.04 (I.44 to 2.89$)$ & $<0.001$ \\
\hline TNM stage (I/II/III) & 3.29 (2.68 to 4.04$)$ & $<0.001$ & $1.92(1.42$ to 2.60$)$ & $<0.001$ \\
\hline Neutrophils $\left(<7.5 / \geq 7.5 \times 10^{9} / \mathrm{L}\right)$ & 2.00 ( 1.46 to 2.73$)$ & $<0.001$ & - & \\
\hline Lymphocytes $\left(<3 / \geq 3 \times 10^{9} / L\right)$ & $0.93(0.64$ to I.35) & 0.70 & - & \\
\hline Platelet $\left(<400 / \geq 400 \times 10^{9} / \mathrm{L}\right)$ & $0.94(0.67$ to I.33) & 0.72 & - & \\
\hline $\operatorname{CRP}(\leq 10 />10 \mathrm{mg} / \mathrm{L})$ & $\mathrm{I} .89$ (I.47 to 2.43$)$ & $<0.001$ & I.I8 (0.90 to I.56) & 0.24 \\
\hline Albumin $(<35 / \geq 35 \mathrm{~g} / \mathrm{L})$ & 1.59 ( 1.22 to 2.063$)$ & 0.001 & - & \\
\hline $\operatorname{NLR}(<2.3 / \geq 2.3)$ & 1.66 (1.39 to 1.99$)$ & 0.001 & - & \\
\hline $\operatorname{PLR}(<|| 7|\geq| \mid 7)$ & $1.28(\mathrm{I} .06$ to $\mathrm{I} .54)$ & 0.009 & $\mathrm{I} .04$ (0.82 to I.32) & 0.75 \\
\hline GPS $(0 / 1 / 2)$ & 1.60 (I.37 to 1.89$)$ & $<0.001$ & - & \\
\hline COA-NLR (0/I/2) & I.54 (I.34 to I.77) & $<0.001$ & 1.35 (I.12 to 1.63$)$ & 0.002 \\
\hline
\end{tabular}

Abbreviations: $\mathrm{Cl}$, confidence interval; COA-NLR, the combination of albumin level and neutrophil lymphocyte ratio; CRP, C-reactive protein; GPS, Glasgow prognostic score; HR, hazard ratio; NLR, neutrophil lymphocyte ratio; PLR, platelet lymphocyte ratio; TNM, tumor-node-metastasis staging.

data suggested that the COA-NLR might have more prognostic value than the PLR in these patients. In fact, Kim et al drove a similar conclusion that the NLR, rather than the PLR, was an independent prognostic factor for GC. ${ }^{11}$ Future studies are needed to further assess the potential prognostic value of the PLR in GC.

In our study, adjuvant chemotherapy was not associated with OS in the unadjusted analysis, although mean survival time was longer in patients with adjuvant chemotherapy than in those without adjuvant chemotherapy (74.5 vs 80.2 months), a finding consistent with Han et al. ${ }^{38}$ They retrospectively analyzed 7,954 patients undergoing D2 gastrectomy for GC in Korea. Multivariate analysis identified age, sex, location, depth of invasion, number of metastatic lymph nodes, and number of examined lymph

Table 5 Areas under the receiver operating characteristic curves for four inflammation-based prognostic indexes for predicting postoperative survival in 873 patients undergoing curative resection without neoadjuvant treatment for gastric cancer

\begin{tabular}{lll}
\hline Index & $\begin{array}{l}\text { Area under the ROC } \\
\text { curve }(95 \% \mathbf{C I})\end{array}$ & P-value \\
\hline COA-NLR & $0.62(0.57$ to 0.66$)$ & $<0.001$ \\
Neutrophil lymphocyte ratio & $0.60(0.55$ to 0.64$)$ & $<0.00$ I \\
Glasgow prognostic score & $0.58(0.54$ to 0.63$)$ & $<0.00$ I \\
Platelet lymphocyte ratio & $0.54(0.50$ to 0.59$)$ & 0.08 \\
\hline
\end{tabular}

Abbreviations: $\mathrm{Cl}$, confidence interval; COA-NLR, the combination of albumin level and neutrophil lymphocyte ratio; ROC, receiver operating characteristic. nodes as covariates associated with survival. However, adjuvant chemotherapy failed to demonstrate significance in the multivariate Cox model. In recent years, several large clinical trials have found substantial benefits of adjuvant

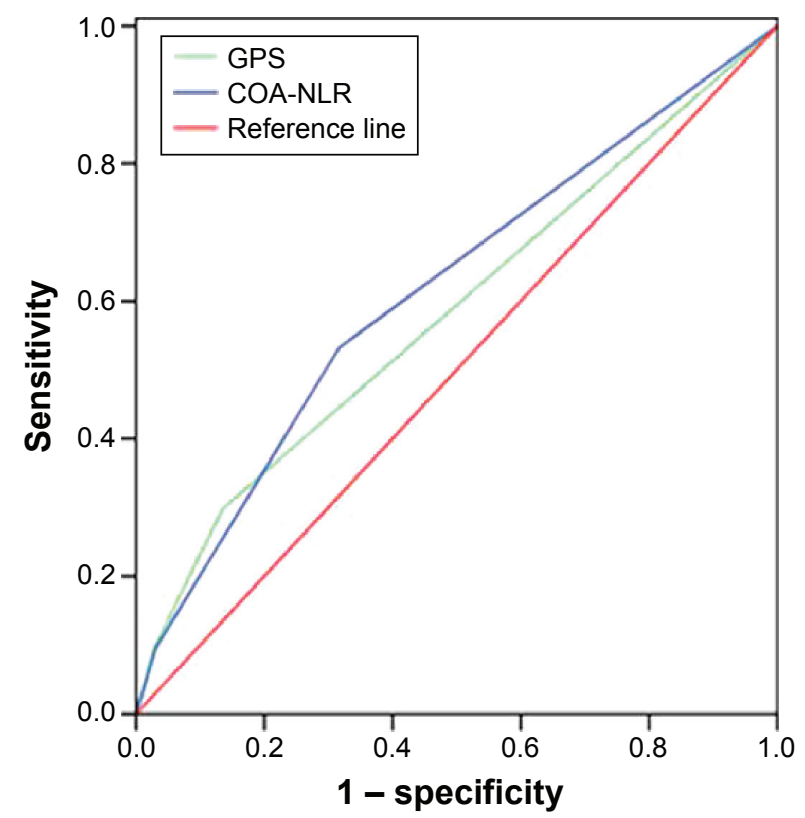

Figure 2 Comparison of the areas under the ROC for predicting overall survival of 873 patients undergoing curative resection without neoadjuvant treatment for gastric cancer $(P<0.001)$.

Abbreviations: COA-NLR, the combination of albumin concentration and neutrophil lymphocyte ratio; GPS, Glasgow prognostic score; ROC, receiver operating characteristic curve. 

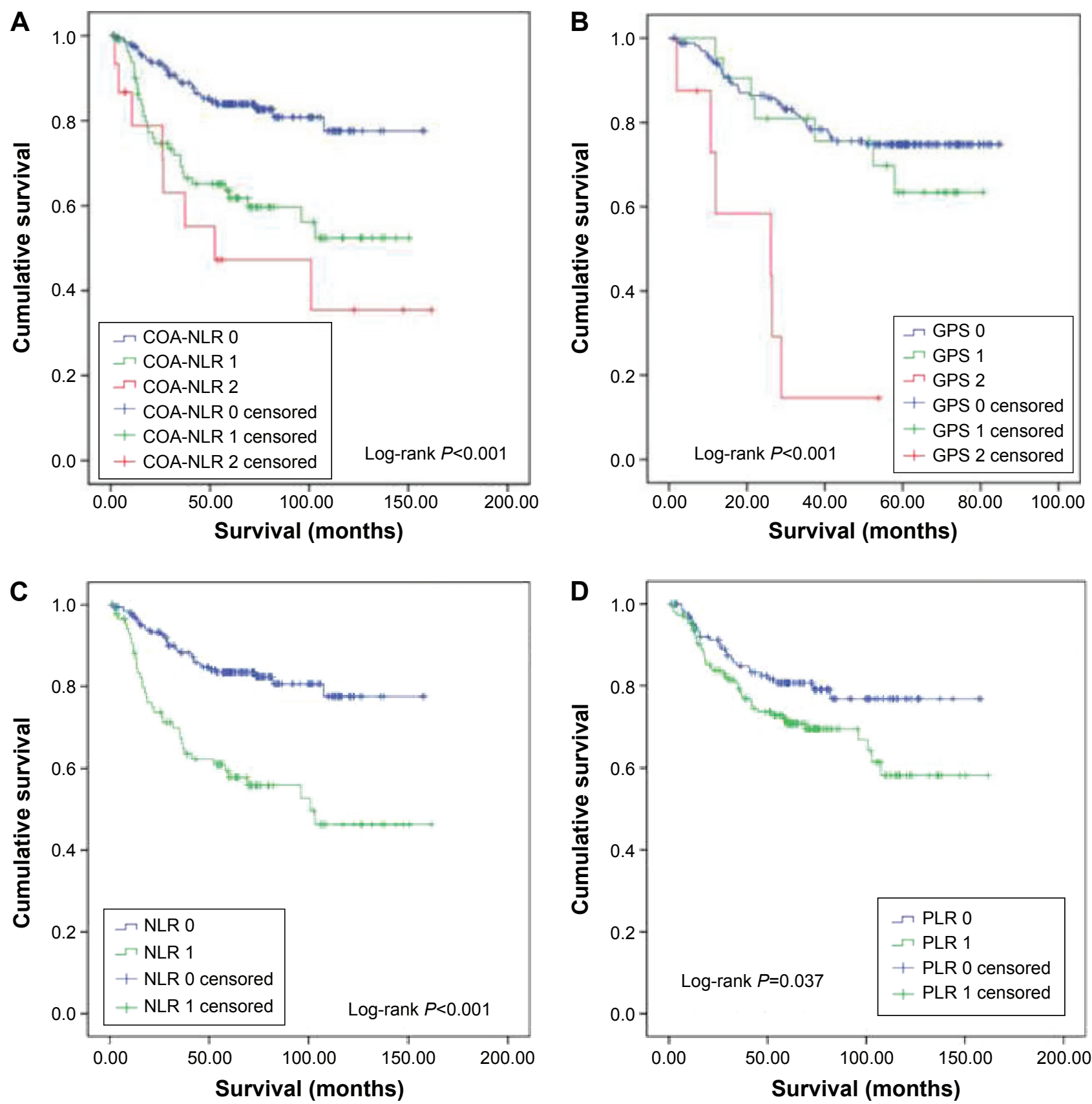

Figure 3 Overall survival in 873 patients with gastric cancer, by preoperative index scores.

Notes: (A) The combination of albumin concentration and neutrophil lymphocyte ratio (COA-NLR; $P<0.00 \mathrm{I}),($ B) the Glasgow prognostic score (GPS; $P<0.00 \mathrm{I}),(\mathbf{C})$ the neutrophil lymphocyte ratio (NLR; $P<0.00 I)$, and $(D)$ the platelet lymphocyte ratio (PLR; $P=0.037$ ) in patients with stage I-II gastric cancer.

Abbreviations: COA-NLR, the combination of albumin concentration and neutrophil lymphocyte ratio; GPS, Glasgow prognostic score; PLR, platelet lymphocyte ratio.

chemotherapy for patients with GC after curative resection, especially in stage-matched analysis. ${ }^{39,40} \mathrm{We}$ speculated some confounding factors, namely TNM stage or adjuvant chemotherapy administration, might influence the prognostic value of adjuvant chemotherapy.

To further evaluate the discriminatory ability of the inflammation-based prognostic scores, we compared the AUCs. The COA-NLR had a higher AUC value than those of the other prognostic scores, suggesting that the
COA-NLR might be a better marker of systemic inflammation and malnutrition than the GPS, PLR, and NLR scores. Therefore, COA-NLR was not only capable of classifying patients with GC into three independent groups before surgery; it was also a potential predictor of OS in such patients.

Our index has predictive capabilities, especially in patients with stage I-II GC, so it may be more suitable for predicting the outcome in such patients than other 
prognostic indexes. Although the survival curve for the NLR is identical to that of patients with a COA-NLR score of 0 , the COA-NLR more accurately assessed prognosis because it has a higher AUC value. OS in patients with a COA-NLR score of 2 was significantly lower than in patients with an NLR score of 1 (35.5\% vs 46.3\%; $P<0.001)$. Obviously, the COA-NLR score could more accurately identify highrisk patients with stage I-II GC. In addition, the COA-NLR score classified patients into three independent groups, which effectively stratifies prognosis in patients undergoing curative resection for GC. More importantly, we found that patients with stage I GC alone had the most to gain from an improved ability to predict poor outcome. It is worthy of being further validated in future studies.

The preoperative COA-NLR score may identify patients with a poor prognosis. If so, resources can be better allocated to patients most at risk, such as closer follow-up and more aggressive adjuvant chemotherapy. In addition, such patients may benefit from targeted anti-inflammatory therapy after surgery. ${ }^{41}$ Furthermore, the COA-NLR score may be able to guide the use of some anti-inflammatory agents. Finally, whether a targeted preoperative nutritional intervention or neoadjuvant therapy could improve outcomes in patients with COA-NLR score of 2 is also worth exploring.

\section{Strengths and limitations of the study}

Limitations of our research include the fact that it was done at a single center and we did not have data on disease-free survival. We also had no information on nutritional support and neoadjuvant therapy. Although the study was retrospective and the number of patients with some scores was small, overall it involved a large and representative sample of patients who underwent uniform surgical procedures, laboratory tests, and follow-up throughout the entire study period. Thus, we believe that the evidence supports the claim that the COA-NLR has prognostic value.

\section{Conclusion}

We believe our study supports the usefulness of the preoperative COA-NLR score for predicting the OS in patients with GC undergoing curative resection without neoadjuvant treatment.

\section{Acknowledgment}

We thank all the people who helped us in this study.

\section{Disclosure}

The authors report no conflicts of interest in this work.

\section{References}

1. Parkin DM, Bray F, Ferlay J, Pisani P. Global cancer statistics, 2002. CA Cancer J Clin. 2005;55(2):74-108.

2. Rahman R, Asombang AW, Ibdah JA. Characteristics of gastric cancer in Asia. World J Gastroenterol. 2014;20(16):4483-4490.

3. Takahashi T, Saikawa Y, Kitagawa Y. Gastric cancer: current status of diagnosis and treatment. Cancers (Basel). 2013;5(1):48-63.

4. Hanahan D, Weinberg RA. Hallmarks of cancer: the next generation. Cell. 2011;144(5):646-674.

5. Nikitovic D, Tzardi M, Berdiaki A, Tsatsakis A, Tzanakakis GN. Cancer microenvironment and inflammation: role of hyaluronan. Front Immunol. 2015;6:169.

6. Caronni N, Savino B, Bonecchi R. Myeloid cells in cancer-related inflammation. Immunobiology. 2015;220(2):249-253.

7. Mantovani A, Allavena P, Sica A, Balkwill F. Cancer-related inflammation. Nature. 2008;454(7203):436-444.

8. Okamura Y, Ashida R, Ito T, Sugiura T, Mori K, Uesaka K. Preoperative neutrophil to lymphocyte ratio and prognostic nutritional index predict overall survival after hepatectomy for hepatocellular carcinoma. World J Surg. 2015;39(6):1501-1509.

9. Park JH, Watt DG, Roxburgh CS, Horgan PG, McMillan DC. Colorectal cancer, systemic inflammation, and outcome: staging the tumor and staging the host. Ann Surg. 2015;263(2):326-336.

10. Imrie $\mathrm{CW}$. Host systemic inflammatory response influences outcome in pancreatic cancer. Pancreatology. 2015;15(4):327-330.

11. Kim EY, Lee JW, Yoo HM, Park CH, Song KY. The platelet-tolymphocyte ratio versus neutrophil-to-lymphocyte ratio: which is better as a prognostic factor in gastric cancer? Ann Surg Oncol. 2015;22(13): 4363-4370.

12. Zhou X, Du Y, Huang Z, et al. Prognostic value of PLR in various cancers: a meta-analysis. PLoS One. 2014;9(6):e101119.

13. Wang DS, Ren C, Qiu MZ, et al. Comparison of the prognostic value of various preoperative inflammation-based factors in patients with stage III gastric cancer. Tumour Biol. 2012;33(3):749-756.

14. Gao Y, Huang D. The value of the systematic inflammation-based Glasgow Prognostic Score in patients with gastric cancer: a literature review. J Cancer Res Ther. 2014;10(4):799-804.

15. Forrest LM, McMillan DC, McArdle CS, Angerson WJ, Dunlop DJ. Evaluation of cumulative prognostic scores based on the systemic inflammatory response in patients with inoperable non-small-cell lung cancer. Br J Cancer. 2003;89(6):1028-1030.

16. Crumley AB, Stuart RC, McKernan M, McMillan DC. Is hypoalbuminemia an independent prognostic factor in patients with gastric cancer? World J Surg. 2010;34(10):2393-2398.

17. Lien YC, Hsieh CC, Wu YC, et al. Preoperative serum albumin level is a prognostic indicator for adenocarcinoma of the gastric cardia. J Gastrointest Surg. 2004;8(8):1041-1048.

18. Chen J, Hong D, Zhai Y, Shen P. Meta-analysis of associations between neutrophil-to-lymphocyte ratio and prognosis of gastric cancer. World J Surg Oncol. 2015;13:122.

19. Washington K. 7th edition of the AJCC cancer staging manual: stomach. Ann Surg Oncol. 2010;17(12):3077-3079.

20. Paoletti X, Oba K, Burzykowski T, et al. Benefit of adjuvant chemotherapy for resectable gastric cancer: a meta-analysis. JAMA. 2010; 303(17):1729-1737.

21. van der Schaaf MK, Tilanus HW, van Lanschot JJ, et al. The influence of preoperative weight loss on the postoperative course after esophageal cancer resection. J Thorac Cardiovasc Surg. 2014;147(1):490-495.

22. Rausei S, Dionigi G, Boni L. Evaluation of the Seventh American Joint Committee on Cancer/International Union Against Cancer Classification of gastric adenocarcinoma in comparison with the sixth classification. Cancer. 2011;117(12):2823-2824; author reply 2824.

23. Proctor MJ, Horgan PG, Talwar D, Fletcher CD, Morrison DS, McMillan DC. Optimization of the systemic inflammation-based Glasgow prognostic score: a Glasgow Inflammation Outcome Study. Cancer. 2013; 119(12):2325-2332. 
24. Liu X, Sun X, Liu J, et al. Preoperative C-reactive protein/albumin ratio predicts prognosis of patients after curative resection for gastric cancer. Transl Oncol. 2015;8(4):339-345.

25. Leitch EF, Chakrabarti M, Crozier JE, et al. Comparison of the prognostic value of selected markers of the systemic inflammatory response in patients with colorectal cancer. Br J Cancer. 2007;97(9):1266-1270.

26. Elinav E, Nowarski R, Thaiss CA, Hu B, Jin C, Flavell RA Inflammation-induced cancer: crosstalk between tumours, immune cells and microorganisms. Nat Rev Cancer. 2013;13(11):759-771.

27. Balkwill F, Mantovani A. Inflammation and cancer: back to Virchow? Lancet. 2001;357(9255):539-545.

28. Kundu JK, Surh YJ. Inflammation: gearing the journey to cancer. Mutat Res. 2008;659(1-2):15-30.

29. Sica A. Role of tumour-associated macrophages in cancer-related inflammation. Exp Oncol. 2010;32(3):153-158.

30. Yang JJ, Hu ZG, Shi WX, Deng T, He SQ, Yuan SG. Prognostic significance of neutrophil to lymphocyte ratio in pancreatic cancer: a meta-analysis. World J Gastroenterol. 2015;21(9):2807-2815.

31. Li QQ, Lu ZH, Yang L, et al. Neutrophil count and the inflammationbased Glasgow prognostic score predict survival in patients with advanced gastric cancer receiving first-line chemotherapy. Asian Pac J Cancer Prev. 2014;15(2):945-950.

32. Supoken A, Kleebkaow P, Chumworathayi B, Luanratanakorn S, Kietpeerakool C. Elevated preoperative platelet to lymphocyte ratio associated with decreased survival of women with ovarian clear cell carcinoma. Asian Pac J Cancer Prev. 2014;15(24):10831-10836.

33. Zhang X, Zhang W, Feng LJ. Prognostic significance of neutrophil lymphocyte ratio in patients with gastric cancer: a meta-analysis. PLoS One. 2014;9(11):e111906.
34. Al-Shaiba R, McMillan DC, Angerson WJ, Leen E, McArdle CS, Horgan $\mathrm{P}$. The relationship between hypoalbuminaemia, tumour volume and the systemic inflammatory response in patients with colorectal liver metastases. Br J Cancer. 2004;91(2):205-207.

35. Borda F, Borda A, Jimenez J, et al. Predictive value of pre-treatment hypoalbuminemia in prognosis of resected colorectal cancer. Gastroenterol Hepatol. 2014;37(5):289-295.

36. Seebacher V, Grimm C, Reinthaller A, et al. The value of serum albumin as a novel independent marker for prognosis in patients with endometrial cancer. Eur J Obstet Gynecol Reprod Biol. 2013;171(1):101-106.

37. Ku JH, Kim M, Choi WS, Kwak C, Kim HH. Preoperative serum albumin as a prognostic factor in patients with upper urinary tract urothelial carcinoma. Int Braz J Urol. 2014;40(6):753-762.

38. Han DS, Suh YS, Kong SH, et al. Nomogram predicting long-term survival after D2 gastrectomy for gastric cancer. J Clin Oncol. 2012; 30(31):3834-3840.

39. Sakuramoto S, Sasako M, Yamaguchi T, et al. Adjuvant chemotherapy for gastric cancer with S-1, an oral fluoropyrimidine. $N$ Engl J Med. 2007;357(18):1810-1820.

40. Noh SH, Park SR, Yang HK, et al. Adjuvant capecitabine plus oxaliplatin for gastric cancer after D2 gastrectomy (CLASSIC): 5-year follow-up of an open-label, randomised phase 3 trial. Lancet Oncol. 2014;15(12): 1389-1396.

41. Jalving M, Koornstra JJ, De Jong S, De Vries EG, Kleibeuker JH. Review article: the potential of combinational regimen with nonsteroidal anti-inflammatory drugs in the chemoprevention of colorectal cancer. Aliment Pharmacol Ther. 2005;21(4):321-339.
OncoTargets and Therapy

\section{Publish your work in this journal}

OncoTargets and Therapy is an international, peer-reviewed, open access journal focusing on the pathological basis of all cancers, potential targets for therapy and treatment protocols employed to improve the management of cancer patients. The journal also focuses on the impact of management programs and new therapeutic agents and protocols on

\section{Dovepress}

patient perspectives such as quality of life, adherence and satisfaction. The manuscript management system is completely online and includes a very quick and fair peer-review system, which is all easy to use. Visit http://www.dovepress.com/testimonials.php to read real quotes from published authors. 